\title{
Process optimisation for ready to eat Indian mackerel (Rastrelliger kanagurta) curry in high impact polypropylene (HIPP) containers using still water spray retort
}

\author{
AMMU DINAKARAN, C. O. MOHAN, SATYEN KUMAR PANDA, C. N. RAVISHANKAR \\ AND T. K. SRINIVASA GOPAL \\ ICAR-Central Institute of Fisheries Technology, Willingdon Island, Matsyapuri P.O., Kochi - 682 029, Kerala, India \\ e-mail: tksgopal1952@gmail.com
}

\begin{abstract}
Mackerel curry is a traditional food which is considered as a delicacy in Kerala. Indian mackerel curry was prepared as per standard recipe and hot filled into high impact polypropylene (HIPP) containers. Dynopack sealing machine was used for top sealing using seethrough films comprising polyester, silicone dioxide coated nylon and cast polypropylene and processed in a still water spray retort at $121.1^{\circ} \mathrm{C}$ to different $\mathrm{F}_{0}$ values of 6,7 and $8 \mathrm{~min}$. Based on the sensory and commercial sterility test, $F_{0}$ value of 8 min was found to be optimum for mackerel in curry medium. The fish curry processed to $F_{0}$ value of 8 was taken up for storage studies at ambient temperature $\left(28 \pm 2^{\circ} \mathrm{C}\right)$ and changes in biochemical parameters like thiobarbituric acid (TBA), total volatile base nitrogen (TVBN), trimethylamine (TMA), instrumental colour and texture were analysed. Upon thermal processing, significant increase in chewiness as well as springiness and decrease in hardness was observed for mackerel at optimum $\mathrm{F}_{0}$ value. The product was found to be commercially sterile throughout the period of storage and was found to have a shelf life of 75 days.
\end{abstract}

Keywords: $\mathrm{F}_{0}$ value, HIPP containers, Indian mackerel, Instrumental colour, Texture profile analysis, Thermal processing, Water immersion retort

\section{Introduction}

Convenience food is a concept that is prevalent in the developed world since long, while its inception into the Indian market has been recent. With the changing socio-economic pattern of life and the increasing number of working couples, the concept is becoming popular in Indian market as it saves time and labour. This has resulted in increased demand for ready to eat food in recent years. Consumers are becoming increasingly aware of the nutritional content, toxic factor, microbiological quality and preservative free products while purchasing food. Preservation of food by thermal processing especially in retoratable pouches will help in providing preservative free products with extended storage life as well as improved nutritional benefits compared to metal containers. Retortable pouches having three layer configuration of polyester/aluminium foil/cast polypropylene can perform the packaging function as that of metal cans and is free from disadvantages like poor barrier properties, pin holing and poor seal strength (Srinivasa Gopal et al., 1998; Vijayan et al., 1998). Fish curries packed in retortable pouches and processed in steam air mixture using over pressure autoclave were found to be in acceptable condition for more than one year at ambient storage
(Srinivasa Gopal et al., 2001; Sonaji et al., 2002; Manju et al., 2004; Ravishankar et al., 2002, 2008; Mohan et al., 2006, 2008, 2014, 2015). Compared to steam-air retorts, water immersion and still water spray retorts are found to be advantageous as the air pockets will not be formed inside the retort in latter types (Hardt-English, 2003). Faster heating rate and better nutrient retention is another advantage of using water spray and water immersion retorts (Mary et al., 2016). Of late, semi-rigid containers are gaining importance for thermal processing. Semi rigid containers have the advantages that they can be formed in any shape i.e., round, square, rectangle or hexagonal with varied depth for different volumes. Apart from this, they can also be used as eating bowl due to their rigidness. These containers are either made of multi-layer with many layers of polypropylene and ethylene vinyl alcohol or with high impact polyprolylene (HIPP). Semi-rigid containers made of HIPP are found to be suitable for food contact applications and have good barrier properties (Mohan, 2008). These containers can also be made locally and are cheaper compared to many commercially available containers.

Fish curry is a traditional food which is considered a delicacy. Mackerel or sardine are most commonly 
available fish species and is consumed in different forms all along the coastal belt of Kerala. They have high moisture content and have a limited storage life at ambient temperature. In order to ensure their distribution and long term storage, it is necessary to preserve them suitably. This will take care of food as well as nutritional security. No work has been carried out in India so far, on the use of semi rigid containers for thermal processing of fish curry using water immersion retort. Hence in this study, attempts have been made to standardise process parameters for the development of ready to eat mackerel curry in thermoformed containers which can be stored at ambient temperatures by subjecting the products to thermal processing using water immersion retort.

\section{Materials and methods}

\section{Physical properties of the packaging materials}

The high impact polypropylene trays were purchased from Kalyx Plasti Pack, Kannur, Kerala. Analyses of physicochemical properties of HIPP trays indicated its suitability for thermal processing. The thickness of the HIPP trays and the top sealing layer was measured as per ASTM (1964). Tensile strength and elongation at break were determined using Universal Testing Machine (Lloyd Instruments LRX plus, UK) and expressed as $\mathrm{kg} \mathrm{cm}^{-2}$ and percentage $(\%)$, respectively. Heat seal strength of the film used for sealing HIPP trays was determined as per ASTM-1434 (1973) and bond strength as perASTM(1972). Water vapour transmission rate was determined according to ASTM-E-96-80 (1987) and gas transmission rate as per ASTM-D-1434 (1975). Suitability of the containers for food contact application was determined following IS: 9845 (1981).

\section{Thermal processing}

Indian mackerel (Rastrelliger kanagurta) $(119 \pm 4.5 \mathrm{~kg}$ weight and $15.2 \pm 2.8 \mathrm{~cm}$ length) purchased from the local market was gutted, beheaded, washed thoroughly in potable water and then blanched in $10 \%$ brine for $30 \mathrm{~min}$ at $27^{\circ} \mathrm{C}$ and drained. Mackerel curry out of $1000 \mathrm{~g}$ of dressed fish was prepared using the following ingredients: tomato $500 \mathrm{~g}$, onion $60 \mathrm{~g}$, ginger $13 \mathrm{~g}$, green chilly $25 \mathrm{~g}$, turmeric powder $2.5 \mathrm{~g}$, coriander powder $20 \mathrm{~g}$, chilly powder $60 \mathrm{~g}$, fenugreek $0.8 \mathrm{~g}$, Malabar tamarind $50 \mathrm{~g}$, oil $50 \mathrm{~g}$, salt $16 \mathrm{~g}$ and water $500 \mathrm{ml}$. Onion and tomato were chopped and ground separately in a mixer. The onion slurry was heated in oil till the colour became light brown. At this stage, ground tomato was added and heating continued for $10 \mathrm{~min}$. Chilly powder, coriander powder and turmeric powder were added to green chilly and ginger which were fried separately in oil and heated under a low flame. The fried ingredients were added to the boiling onion-tomato slurry and heating continued. Potable water was added to adjust the consistency of the curry. Ninety gram of fish and $60 \mathrm{~g}$ of curry was packed together in HIPP trays of size $12.5 \times 9.2 \times 2.5 \mathrm{~cm}$ (length $\mathrm{x}$ breadth $\mathrm{x}$ height) having $220 \mathrm{ml}$ capacity, in order to maintain a 60:40 solid liquid ratio. The curry was filled under hot conditions to facilitate the removal of air in the head space. The trays were sealed on top with seethrough film made of three layers viz., outer polyester (PEST), middle nylon coated with silicon dioxide and inner layer of cast polypropylene (CPP) using heat sealing machine (Dynopack Industries, Hyderabad, India). Initially the cold point in the water immersion retort was standardised by placing thermocouples of Ellab SSA-12050-G700-TS stainless steel electrode (50 mm length; $1.2 \mathrm{~mm}$ dia) in different positions of the retort and heat penetration studies were carried out by monitoring the temperature of the product placed in the point. Minimum three containers were fixed with glands and thermocouples, the tips of which were inserted into a piece of fish. The filled and sealed trays were laid flat on the trays in a water immersion retort (Lakshmi Engineering Works, Chennai, Tamil Nadu, India). Processing media was water sprayed at a high pressure (28 psi) inside in a mist like formation, which was collected at the bottom and then directed to a circulation line. Steam is admitted into the circulation line and also directly inside the retort. The sprayed water absorbs the heat from incoming steam and transmits the same to the products. The thermocouple output was measured using an Ellab E-Val Flex, 14592 data recorder. The products were processed to different $\mathrm{F}_{0}$ values of 6,7 and 8 min at the retort temperature maintained at $121.1^{\circ} \mathrm{C}$.

Rapid cooling was done by cutting off the steam supply and recirculation of cooling water. The trays were unloaded from the retort when the core temperature reached around $30^{\circ} \mathrm{C}$. The recorded data was analysed and heat penetration data were plotted on a log paper with temperature deficit (retort temperature-core temperature) against time. Lag factor for heating $\left(\mathrm{J}_{\mathrm{h}}\right)$, slope of the heating curve $\left(\mathrm{f}_{\mathrm{h}}\right)$, initial temperature deficit (I), final temperature deficit $(\mathrm{g})$, time in minutes for sterilisation at retort temperature $(\mathrm{U})$ and lag factor for cooling $\left(\mathrm{J}_{\mathrm{c}}\right)$ were determined. The Ball's process time (B) was calculated by Formula method (Ball, 1923). Total process time (T) was determined by adding Ball's process time (B) and the effective heating period during come up time i.e., $58 \%$ of the come up time (Stumbo, 1973).

$$
\begin{aligned}
& \text { Ball's process time }(B)=f_{h}\left[\log \left(\operatorname{IxJ}_{h}\right)-\log g\right] \\
& \text { Total process time }(T)=B+58 \% \text { of come up time }
\end{aligned}
$$

To standardise the optimum process conditions for the thermal processing of mackerel fish curry, processing was done at three different $\mathrm{F}_{0}$ values and tests for 
commercial sterility, colour analysis, texture profile analysis and sensory evaluation were carried out.

Based on the results, an $\mathrm{F}_{0}$ value was chosen according to which mackerel fish curry was prepared on a pilot scale for the evaluation of its shelf life at ambient temperature. Samples were taken at regular intervals of 15 days and were analysed for instrumental colour, texture profile, thiobarbituric acid (TBA), total volatile base nitrogen (TVBN), trimethylamine (TMA), peroxide value (PV), free fatty acid (FFA) and sensory characteristics.

\section{Commercial sterility}

Commercial sterility of the processed samples were tested as per IS: 2168 (1971) to assess the adequacy of lethality.

\section{Analysis of colour}

Colour measurements were done using a Hunter Lab colourimeter (Miniscan XE Plus, Model No D/ 8-S) with geometry of diffuse $/ 8^{\circ}$ (sphere $8 \mathrm{~mm}$ view) and an illuminant of D65/10 deg. Fish meat was blended and the colour was measured to get the homogeneous colour of meat.

\section{Texture profile analysis}

Texture profile analysis were carried out using the food texture analyser (Lloyd Instruments, Model LRX plus F.T-39 No-2, UK) with the help of Nexygen software. Fish pieces with a sample size of $2 \times 2 \mathrm{~cm}$ (length $\mathrm{x}$ breadth) and thickness of $1 \mathrm{~cm}$ was cut from the dorsal portion of fish and used for texture analysis. Cylindrical probe with $50 \mathrm{~mm}$ dia was used for texture analysis at a speed of $12 \mathrm{~mm} \mathrm{sec}^{-1}$ and trigger force of $1 \mathrm{~N}$ using $500 \mathrm{~N}$ load cell. Compression of $40 \%$ was used.

\section{Biochemical analysis}

Proximate composition of fresh Indian mackerel was analysed following AOAC (2000). Storage studies were carried out at ambient temperature $\left(28 \pm 2^{\circ} \mathrm{C}\right)$. The product was analysed at regular intervals of every 15 days for changes in their biochemical characteristics like $\mathrm{pH}, \mathrm{TBA}$, TVBN, TMA, PV and FFA. $\mathrm{pH}$ was determined using a glass electrode digital $\mathrm{pH}$ meter after homogenising the sample using distilled water $(1: 5 \mathrm{w} / \mathrm{v})$. TBA value was determined spectrophotometrically from an acidified distillate of the sample to assess the oxidation stability of the product (Tarladgis et al., 1960). TVBN and TMA were estimated by preparing a 10\% tri-chloro acetic acid (TCA) extract of the sample using microdiffusion method (Conway, 1950). PV was estimated by preparing a chloroform extract of the curry sample followed by its iodometric titration (Yildiz et al., 2003). The chloroform extract was used for determination of FFA value as per AOAC (1989).

\section{Sensory evaluation}

Sensory evaluation based on characterisation and differentiation of the various sensory characters such as colour, flavour, texture and overall acceptability were evaluated by a panel of 10 trained judges on a 10-point scale (IS: 6273(II) 1971). The panelists were asked to assign a score of 1-10 as prescribed by Vijayan and Balachandran (1986). A sensory score of 4.0 was taken as the margin of acceptance.

Statistical analysis

A minimum of three containers were monitored for time temperature data. Triplicate samples were used for all the biochemical and physical analyses. A minimum of ten samples were used for testing packaging materials. Analysis of variance (ANOVA) was used to define the significance of differences $(\mathrm{p}<0.05)$.

\section{Results and discussion}

\section{Physical properties of the packaging materials}

Physico-chemical properties of the packaging materials used for packing food provides useful information on their suitability for different processing conditions. The HIPP trays used for processing had a thickness of $996 \pm 1.2 \mu \mathrm{m}$. Tensile strength was $332 \pm 1.6$ and $306 \pm 1.1 \mathrm{~kg} \mathrm{~cm}^{-2}$ in the machine direction and cross direction respectively. The elongation at break for machine direction and cross direction was $92 \pm 3.54 \%$ and $98 \pm 2.25 \%$ respectively. Water vapour transmission rate was $0.76 \pm 0.05 \mathrm{~g} \mathrm{~m}^{-2} 24 \mathrm{~h}^{-1}$ at $37^{\circ} \mathrm{C}$ and $92 \%$ relative humidity (RH). Oxygen transmission rate was $9.5 \pm 0.14 \mathrm{cc} \mathrm{m}^{-2} 24 \mathrm{~h}^{-1}$ at 1 atm pressure. Overall migration residue test was carried out to assess the suitability for food contact applications and the results obtained were $5.4 \pm 0.32 \mathrm{mg} \mathrm{l}^{-1}$ water extractives, $3.6 \pm 0.16$ $\mathrm{mg}^{-1} n$-heptane extractives and $2.14 \pm 0.21 \mathrm{mg} \mathrm{l}^{-1} 3 \%$ acetic acid extractives. The results indicate that the overall migration residue for HIPP tray was $<12 \mathrm{mg} \mathrm{l}^{-1}$ which is well below the acceptable limit of $60 \mathrm{mg} \mathrm{l}^{-1}$, indicating its suitability for food contact applications. The seethrough film comprising PEST, silicon dioxide coated nylon- and CPP, which was used as top sealing material had a thickness of $100 \pm 0.01 \mu \mathrm{m}$. Tensile strength was $782 \pm 0.01$ and $615 \pm 0.01 \mathrm{~kg} \mathrm{~cm}^{-2}$ in the machine direction and cross direction respectively. Heat seal strength for machine direction and cross direction was $562 \pm 1.1$ and $439 \pm 1.3 \mathrm{~kg} \mathrm{~cm}^{-2}$ respectively. Elongation at break for machine direction and cross direction was $82 \pm 0.02$ and $96 \pm 0.03 \%$ respectively and the bond strength was $132 \pm 0.3 \mathrm{~g}$ per $10 \mathrm{~mm}$. The water vapour transmission rate was $0.95 \pm .01 \mathrm{~g} \mathrm{~m}^{-2} 24 \mathrm{~h}^{-1}$ at $37^{\circ} \mathrm{C}$ and $92 \% \mathrm{RH}$ and 
oxygen transmission rate was $2.14 \pm .01 \mathrm{cc} \mathrm{m}^{-2} 24 \mathrm{~h}^{-1}$ at $1 \mathrm{~atm}$ pressure. Overall migration residue test was carried out to know the suitability for food contact applications and the results obtained were $4.5 \pm 0.16 \mathrm{mg} \mathrm{l}^{-1}$ water

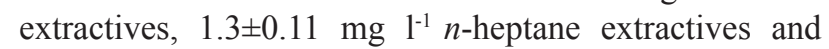
$1.88 \pm 0.23 \mathrm{mg} \mathrm{l}^{-1} 3 \%$ acetic acid extractives. The film used for top sealing of the trays had an outer polyester layer, middle silicon dioxide coated nylon and an inner layer of cast polypropylene. Silicon dioxide is a nanoparticle, specially incorporated to provide good barrier properties. Analyses of the physical properties indicated that the packaging material can withstand thermal processing temperature of $121.1^{\circ} \mathrm{C}$. The results also revealed that it can withstand a working pressure of 28 psig. The HIPP trays did not change shape during retorting and were found to be ideal for thermal processing.

\section{Heat penetration characteristics}

The water immersion retort showed uniform heating in all parts of the processing chamber with a variation of only $\pm 1^{\circ} \mathrm{C}$. The $\mathrm{F}_{0}$ recommended for fish and fish products ranges from 5-20 min (Frott and Lewis, 1994). Mackerel curry in trays was heat processed for $\mathrm{F}_{0} 6,7$ and 8 . Curry processed at $\mathrm{F}_{0} 8$ using water spray in the water immersion retort was found to be sterile. Heat penetration characteristics of mackerel in curry medium processed at $\mathrm{F}_{0} 8.1$ are shown in Table 1. The come up time to attain $121.1^{\circ} \mathrm{C}$ was 9 min for mackerel in curry medium and it has been reported that the come up time should be kept as short as possible (NCA, 1968). The actual process time for mackerel curry to $\mathrm{F}_{0} 8.1$ was $40.55 \mathrm{~min}$.

Table 1. Heat penetration characteristics of mackerel curry

\begin{tabular}{ll}
\hline Parameters & Mackerel $\mathrm{F}_{0} 8.1$ \\
\hline $\mathrm{J}_{\mathrm{h}}$ & 0.89 \\
$\mathrm{~J}_{\mathrm{c}}$ & 0.91 \\
$f_{h}$ & $19 \mathrm{~min}$ \\
$\mathrm{U}$ & $8.1 \mathrm{~min}$ \\
$f_{h} / U$ & 2.34 \\
$G$ & 1.10511 \\
$\mathrm{~B}$ & $35.33 \mathrm{~min}$ \\
$\mathrm{CUT}$ & $9 \mathrm{~min}$ \\
$\mathrm{TPT}$ & $40.55 \mathrm{~min}$ \\
$\mathrm{Cg}$ & $82.59 \mathrm{~min}$ \\
\hline
\end{tabular}

where, $J_{h}=$ lag factor of heating, $f_{h}=$ slope of heating curve, $\mathrm{U}=$ time in minutes for sterilisation at retort temperature, $g=$ final temperature deficit, $\mathrm{B}=$ Ball's process time, $\mathrm{CUT}=$ come up time, $\mathrm{TPT}=$ Total process time, $\mathrm{Cg}=$ Cook value

The core temperature, retort temperature and $\mathrm{F}_{0}$ for processing of mackerel curry are shown in Fig. 1. Retort temperature showed a sudden decrease as soon as the steam was cut off and cold water was circulated. This is necessary because the product should be cooled

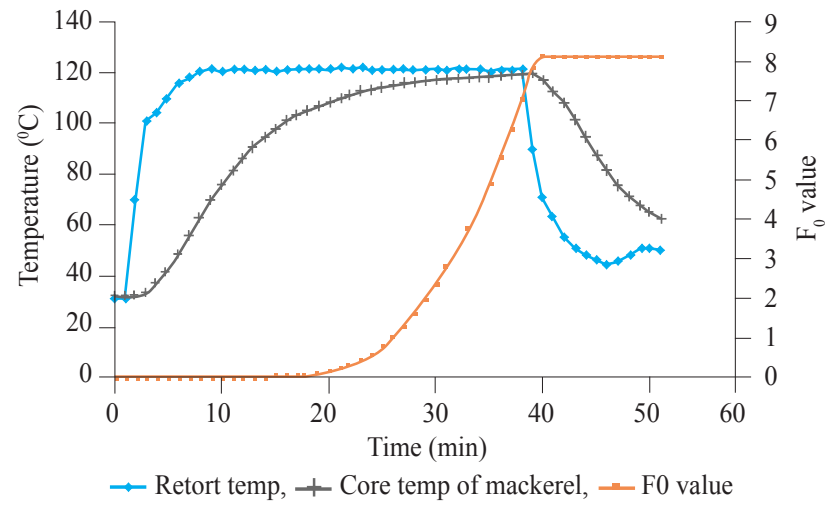

Fig. 1. Heat penetration and $\mathrm{F}_{0}$ value of mackerel in curry medium as soon as possible to avoid overcooking and to prevent growth of thermophiles. Fig. 2 depicts heat penetration characteristics with respect to cook value for mackerel.

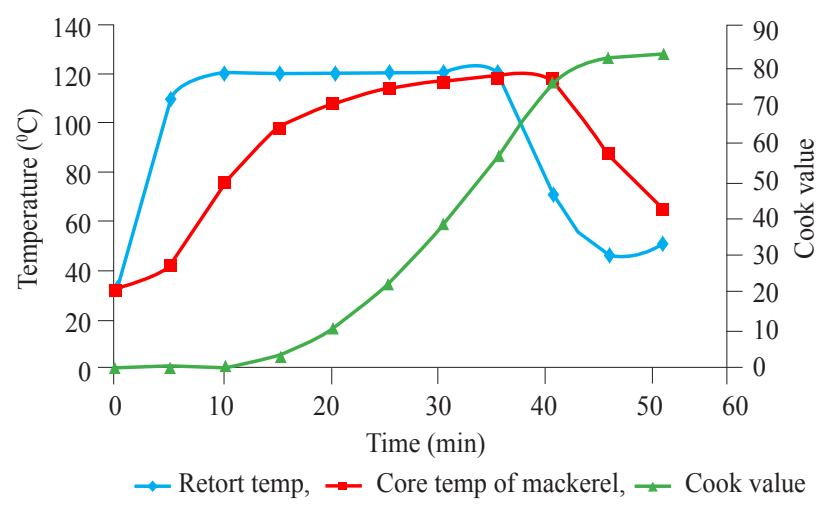

Fig. 2. Heat penetration and cook value of mackerel in curry medium

Proximate composition of Indian mackerel

Proximate composition of mackerel used for processing showed a moisture content of $77.63 \pm 0.01$, ash content of $1.55 \pm 0$, fat content of $1.59 \pm 0$ and a protein content of $20.55 \pm 0.21 \%$.

\section{Colour analysis}

Table 2 summarises the colour values for mackerel fish curry during the period of storage. The increase in $\mathrm{L}^{*}$ value of processed mackerel compared to that of raw mackerel is due to the leaching of muscle pigments during pre-cooking and thermal processing and leaching of white connective tissue containing collagen during heat processing (Mohan et al., 2015). The $\mathrm{a}^{*}$ and $\mathrm{b}^{*}$ values showed increasing trend because of the absorption of spices like chilly powder and turmeric powder respectively and maillard reaction between sugar and amino acids.

\section{Texture profile analysis}

Table 3 shows the different parameters of texture profile analysis of mackerel curry processed to $F_{0}$ value 
Table 2. Colour analysis of mackerel fish curry

\begin{tabular}{llll}
\hline Days of storage & $\mathrm{L}^{*}$ & $\mathrm{a}^{*}$ & $\mathrm{~b}^{*}$ \\
\hline 0 & $38.87 \pm 0.09$ & $5.01 \pm 0.05$ & $10.77 \pm 0.08$ \\
15 & $57.12 \pm 0.08$ & $6.66 \pm 0.08$ & $24.25 \pm 0.08$ \\
30 & $56.90 \pm 0.06$ & $6.79 \pm 0.04$ & $25.58 \pm 0.02$ \\
45 & $54.62 \pm 0.09$ & $6.97 \pm 0.05$ & $26.39 \pm 0.22$ \\
60 & $52.96 \pm 0.13$ & $7.65 \pm 0.1$ & $27.42 \pm 0.09$ \\
75 & $52.39 \pm 0.07$ & $7.93 \pm 0.04$ & $27.87 \pm 0.05$ \\
90 & $51.28 \pm 0.04$ & $7.98 \pm 0.01$ & $27.89 \pm 0.01$ \\
\hline
\end{tabular}

sterlisation steps. It reached a maximum limit of $31.5 \mathrm{mg}$ after 3 months storage at room temperature. TVBN limit for acceptability is $30 \mathrm{mg}$. Sensory evaluation of samples stored for 90 days revealed a sensory score below 5 .

Trimethylamine (TMA), a volatile component represents the majority of TVBN. The average TMA value of raw material was zero which indicates the sample used in the study was in fresh condition. A significant increase

Table 3. Texture profile analysis of mackerel fish curry

\begin{tabular}{lllllll}
\hline Day & Hardness 1 $(\mathrm{N})$ & Hardness 2 $(\mathrm{N})$ & Cohesiveness & Springiness $(\mathrm{mm})$ & Gumminess $(\mathrm{kg}$ f) & Chewiness $(\mathrm{kg} \mathrm{f} \mathrm{mm})$ \\
\hline 0 & $41.02 \pm 0.07$ & $38.28 \pm 0.3$ & $0.09 \pm 0$ & $0.67 \pm 0.02$ & $0.25 \pm 0.03$ & $3.76 \pm 0.15$ \\
30 & $30.69 \pm 0.53$ & $21.72 \pm 0.61$ & $0.11 \pm 0.01$ & $2.54 \pm 0.02$ & $0.35 \pm 0.03$ & $3.70 \pm 0.04$ \\
60 & $25.60 \pm 0.16$ & $19.57 \pm 0.21$ & $0.26 \pm 0.02$ & $4.71 \pm 0.12$ & $0.71 \pm 0.01$ & $3.20 \pm 0.06$ \\
90 & $22.73 \pm 0.10$ & $17.41 \pm 0.13$ & $0.24 \pm 0.02$ & $4.92 \pm 0.04$ & $0.84 \pm 0.03$ & $3.27 \pm 0.07$ \\
\hline
\end{tabular}

of 8.21. Thermal processing led to significant decrease $(\mathrm{p}<0.05)$ in the hardness of the fish pieces in the curry which clearly indicated that cooking leads to softness. The main external factors affecting the texture of fish are temperature of cooking and presence of sodium chloride (Mohan et al., 2014, 2015). Hardness 2 values are always less than those values obtained at first compression. This is because non-compressed samples have a firm texture compared to compressed sample. Texture of fish meat is influenced by the collagen content of the meat as well. When core temperature reaches $92^{\circ} \mathrm{C}$, collagen content of meat is denatured and converted to gelatin. The lowering of hardness values on thermal processing is due to the effect of temperature on collagen and resultant softening of the muscle. Cohesiveness refers to the visco-elasticity of the product. On the initial day, the cohesiveness was 0.09 and it increased to 0.24 on day 90 of storage. The faster heat penetration in HIPP trays led to the increase in cohesiveness (Ansar Ali et al., 2005). Springiness refers to elasticity of the sample, which was $0.67 \mathrm{~mm}$ on the initial day of storage and increased to $4.92 \mathrm{~mm}$ on day 90 of storage. The product showed elastic behaviour throughout the storage period. Gumminess also increased from 0.25 to $0.84 \mathrm{kgf}$. This is in agreement with the findings of Mohan et al. $(2014,2015)$ for thermal processed tuna in cans.

\section{Biochemical analysis}

The changes that occurred in different biochemical parameters of the mackerel fish curry during the period of storage is given in Table 4 .

Total volatile base nitrogen (TVBN) quantified a range of basic volatile compounds including ammonia, methyl amine, dimethyl amine and trimethylamine. The increase in TVBN content is due to thermal breakdown of trimethylamine N-oxide (TMA-O) during cooking and in TMA content was observed during the storage. TMA is produced from TMAO by thermal breakdown during the cooking and sterilisation process. Thermal processing exerted a higher effect on the TMA formation during storage.

TBA value, an index of secondary lipid oxidation showed an increasing trend during storage. The peroxides formed during storage may have decomposed to form compounds including aldehydes such as malonaldehyde which are responsible for increase in TBA value. TBA limit for acceptability is $2 \mathrm{mg}$. It reached more than $2 \mathrm{mg}$ after 3 months storage.

FFA values of fish muscle gives an account of the degree of lipid hydrolysis that occurred during storage. FFA values of samples during storage showed a slight increase on day 15 of storage and decrease during further storage. Same trend was observed in case of peroxide value. There was not much lipid hydrolysis during storage.

\section{Sensory evaluation}

Sensory evaluation of the samples during storage revealed that the product were in acceptable condition upto 75 days at ambient temperature. The overall acceptability score which was obtained by adding all the attributes viz., appearance, colour, odour, flavour, taste and texture is given in Table 5. A final score of 3.8 was obtained on day 90 of storage.

The overall migration from the packaging material is within the limit indicating their suitability for food contact application. For mackerel in curry medium, processing up to $\mathrm{F}_{0}$ value of $8 \mathrm{~min}$ was appropriate. Process time in the water spray retort was $40.55 \mathrm{~min}$ for fish curry. The product was found to be commercially sterile during the entire period of storage. In accordance 
Table 4. Biochemical parameters

\begin{tabular}{llllll}
\hline Days of storage & TBA $(\mathrm{mg} \%$ malonaldehyde $)$ & TVBN $(\mathrm{mg} \%)$ & TMA $(\mathrm{mg} \%)$ & PV $\left(\mathrm{mEqO}_{2} \mathrm{~kg} \mathrm{sample}^{-1}\right)$ & FFA $(\%$ oleic acid $)$ \\
\hline 0 & $0.29 \pm 0$ & $14 \pm 0$ & $0 \pm 0$ & $11.36 \pm 0$ & $8.75 \pm 1.13$ \\
15 & $0.30 \pm 0$ & $16.1 \pm 0.99$ & $1.4 \pm 0$ & $13.75 \pm 0.88$ & $9.63 \pm 1.24$ \\
30 & $0.48 \pm 0$ & $18.2 \pm 0$ & $1.4 \pm 0$ & $14.47 \pm 0.88$ & $6.96 \pm 0.12$ \\
45 & $0.96 \pm 0$ & $21.7 \pm 0.99$ & $5.6 \pm 0$ & $10.78 \pm 0$ & $5.56 \pm 0.10$ \\
60 & $1.16 \pm 0$ & $23.8 \pm 0$ & $11.9 \pm 0.99$ & $13.12 \pm 0.35$ & $6.17 \pm 0.10$ \\
75 & $1.83 \pm 0$ & $28.7 \pm 0.99$ & $20.3 \pm 0.99$ & $10.64 \pm 0.35$ & $6.79 \pm 0$ \\
90 & $2.19 \pm 0$ & $31.5 \pm 0.99$ & $25.2 \pm 0$ & $11.5 \pm 0.71$ & $7.35 \pm 0.10$ \\
\hline
\end{tabular}

Table 5. Overall acceptability score obtained for the product during period of storage

\begin{tabular}{ll}
\hline Days of storage & Overall acceptability \\
\hline 15 & $7.87 \pm 0.06$ \\
30 & $7.07 \pm 0.06$ \\
45 & $6.77 \pm 0.06$ \\
60 & $5.70 \pm 0.1$ \\
75 & $4.70 \pm 0.2$ \\
90 & $3.50 \pm 0.3$ \\
\hline
\end{tabular}

with the chemical parameters and the sensory score assigned by the panel members of sensory evaluation, the product was within the limit of acceptability for a period of 75 days at ambient temperature. The lower shelf life obtained could be attributed to the low barrier properties of the HIPP trays towards oxygen and water vapour. An improvement in the barrier properties of the packaging material could further increase the shelf life of the product.

\section{Acknowledgements}

The authors are thankful to the Kerala State Council for Science Technology and Environment for the financial support provided to carry out the work as a part of the project 'Development of Ready to Eat combination meals in thermoformed containers using Multilayer films'. We acknowledge the whole hearted support given by the Director, ICAR-CIFT, Kochi to carry out the work in the Fish Processing Division of the Institute.

\section{References}

Ansar Ali, Sudhir, B. and Srinivasa Gopal, T. K. 2005. Effect of heat processing on the texture profile of canned and retort pouch packed oilsardine (Sardinella longiceps) in oil medium. J. Food Sci., 70(5): 350-354.

AOAC 1989. Official methods and recommended practices of American Oil Chemists Society, $5^{\text {th }}$ edn. Association of Official Analytical Chemists, Champaign.

AOAC 2000. Official methods of analysis. Association of Official Analytical Chemists International, $17^{\text {th }}$ edn. Gaithersburg, MD.

ASTM-D-1434. 1975. Standard method of test for gas transmission rate of plastic film sheeting, D 1434. American Society for Testing and Materials, Philadelphia, USA.
ASTM 1434. 1973. Standard methods of test for seal strength of flexible barrier materials, American Society for Testing and Materials. Philadelphia, USA.

ASTM-E-96-80. 1987. Standard operating procedure for the determination of water vapour transmission rate E 96-80. American Society for Testing and Materials, Philadelphia, USA.

Ball, C. O. 1923. Thermal process time for canned foods, Bull. 37. National Research Council, Washington DC, USA.

Conway, E. J. 1950. Micro diffusion analysis of volumetric error. Crosby Lockwood and Son Limited, London, UK.

Frott, R. and Lewis, A. S. 1994. Canning of meat and fish products. Chapman and Hall, London, UK, p. 200-202.

Hardt-English, P. K. 2003. Commercial sterilisation systems. In: Dennis R. Heldman (Ed.), Encyclopedia of agricultural, food and biological engineering, Marcel Dekker, Inc., p. $139-142$.

IS: 2168 1971. Specification for pomfret canned in oil. Indian Standards Institute, New Delhi, India.

IS: 6273 (II). 1971. Indian standard, Guide for sensory evaluation offoods, Part II, Methods and evaluation cards. Indian Standards Institute, New Delhi, India.

IS: 9845. 1981. Methods of analysis for the determination of specific or overall migration constituents of plastic materials and articles intended to come into contact with food stuff. Bureau of Indian Standards, New Delhi.

Mary, A. A., Omitoyin, B. O., Mohan, C. O. and Zynudheen, A. A 2016. Heat penetration attributes of milkfish (Chanos chanos) thermal processed in flexible pouches: a comparative study between steam application and water immersion. Food Sci. Nutr., DOI: 10.1002/fsn3.426.

Mohan, C. O. 2008. Shelf life extension of seerfish (Scomberomorus commerson) steaks using $\mathrm{O}_{2}$ scavenger and $\mathrm{CO}_{2}$ emitters in chilled condition. Ph. D. thesis, ICAR-Central Institute of Fisheries Education, Mumbai, India, 248 pp.

Mohan, C. O., Ravishankar, C. N., Bindu, J. and Srinivasa Gopal, T. K. 2008. Thermal processing of prawn 'kuruma' in retortable pouches and aluminium cans. Int. J. Food Sci. Technol., 43: 200-207.

Mohan, C. O., Ravishankar, C. N., Bindu, J., Geethalakshmi, V. and Srinivasa Gopal, T. K. 2006. Effect of thermal process 
time on quality of shrimp kuruma in retortable pouches and aluminium cans. J. Food Sci., 71, S496-S500.

Mohan, C. O., Remya, S., Murthy, L. N., Ravishankar, C. N. and Srinivasa Gopal, T. K. 2015. Effect of filling medium on cooking time and quality of canned yellowfin tuna (Thunnus albacares). Food Control, 50: 320-327.

Mohan, C. O., Remya, S., Ravishankar, C. N., Vijayan, P. K. and Srinivasa Gopal, T. K. 2014. Effect of filling ingredient on the quality of canned yellowfin tuna (Thunnus albacares). Int. J. Food Sci. Technol., 49: 1557-1564.

NCA 1968. Laboratory manual for food canners and processors, vol. 1, National Canners Association, AVI publishing Co., West Port.

Ravishankar, C. N., Bindu, J. and Srinivasa Gopal, T. K. 2008. Ready to serve mackerel curry (Goan style) in retortable pouches. Fishery Technol., 45(2): 171-180.

Ravishankar, C. N., Srinivasa Gopal, T. K. and Vijayan, P. K. 2002. Studies on heat processing and storage of seer fish curry in retort pouches. Package Technol. Sci., 15: 3-7.

Manju, S., Sonaji, E. R., Leema Jose, Srinivasa Gopal, T. K., Ravishankar, C. N. and Vijayan, P. K. 2004. Heat penetration characteristics and shelf life studies of seer fish moilee packed in retort pouches. Fishery Technol., 41(1): 37-44.

Sonaji, E. R., Manju, S., Rashmy, S., Srinivasa Gopal, T. K., Ravishankar, C. N., Vijayan, P. K. and Unnikrishnan Nair, T. S. 2002. Heat penetration characteristics of rohu curry. In: Boopendranath, M. R., Meenakumari, B., Joseph, J., Sankar, T. V., Pravin, P. and Edwin, L. (Eds.), Riverine and reservoir fisheries of India, Society of Fisheries Technologists, Kochi, India, p. 320-324.

Srinivasa Gopal,T. K., Vijayan, P. K., Balachandran, K. K. and Madhavan, P. 1998. Heat penetration of fish curry in retort pouch. In: Advances and priorities in fisheries technology, Society of Fisheries Technologists (India), Kochi, p. 236-241.

Srinivasa Gopal, T. K., Vijayan, P. K., Balachandran, K. K., Madhavan, P. and Iyer, T. S. G. 2001. Traditional Kerala style fish curry in indigenous retort pouch. Food Control, (12): 523-527.

Stumbo, C. R. 1973. Thermo bacteriology in food processing, $2^{\text {nd }}$ edn. Academic Press, New York, USA, p. 93-120.

Tarladgis, G. B., Watts, M. B. and Younathan, T. M. 1960. A distillation method for the quantitative determination of malonaldehyde in rancid foods. J. Am. Oil Chem. Soc., 37: $44-50$

Vijayan, P. K. and Balachandran, K. K. 1986. Development of canned fish curry. Fish. Technol., 23: 57-60.

Vijayan, P. K., Srinivasa Gopal, T. K., Balachandran, K. K. and Madhavan, P. K. 1998. Fish curry in retort pouches. In: Balaachandran, K. K., Iyer, T. S. G., Madhavan, P. K., Joseph, J., Perigreen, P. A., Raghunath, M. R. and Varghese, M. D. (Eds.), Advances and priorities in fisheries technology, Society of Fisheries Technologists (India), Kochi, p. 232-235.

Yildiz, G., Wehling, R. and Cuppet, S. L.2003. Comparison of four analytical methods for the determination of peroxide value in oxidised soy-bean oils. J. Am. Oil Chem. Soc., 80: $103-107$ 